\title{
PERAN GURU PENDIDIKAN AGAM ISLAM DALAM PEMBINAAN AHLAK SISWA DI SEKOLAH MENENGAH PERTAMA AL - AZHAR PAGELARAN MALANG
}

\author{
Alif Achadah \\ Fakultas Ilmu Keislaman Universitas Islam Raden Rahmat Malang \\ achadahalif@gmail.com
}

Diterima: 24 September 2019 | Direvisi: 03 Oktober 2019| Disetujui: 18 November 2019

(C) 2018 Program Studi Pendidikan Agama Islam Fakultas Agama Islam Universitas Islam Malang

\begin{abstract}
Education is a very important thing in human life. When talking about education, it is inseparable about education personnel called teachers. Therefore in this study discussed about the role of teachers of Islamic religious education which is basically a forum for fostering student morals when the students are in the school environment. This study uses qualitative methods that basically collect data from interviews, observations, and observations. With this method it is considered very good for this research so that it can answer the problem. The teacher at this school is very cooperative in improving student morals both at school and outside school.
\end{abstract}

Keyword: Role, Teacher Islamic Education, Moral Development

\begin{abstract}
Abstrak
Pendidikan merupakan hal yang sangat penting dalam kehidupan manusia. Ketika bicara tentang pendidikan, tak dapat dipisahkan tentang tenaga pendidikan yang disebut dengan guru. Oleh sebab itu dalam penlitian ini dibahas tentang peran guru pendidikan agama islam yang dasarnya adalah untuk wadah membina akhlak siswa ketika siswa tersebut dalam lingkungan sekolah. Penelitian ini menggunakan metode kualitatif yang pada dasarnya mengumpulkan data dari wawancara, pengamatan, dan observasi. Dengan metode tersebut dirasa sangat baik untuk penelitian ini sehingga dapat menjawab permasalahan. Guru disekolah ini sangat kooperatif dalam meningkatkan akhlak siswa baik ketika di sekolah amupun diluar sekolah.
\end{abstract}

Kata Kunci: Peran, Guru PAI, Pembinaan Akhlak

\section{Pendahuluan}

Adanya perilaku menyimpang yang akhir - akhir ini terjadi merupakan kenyataan yang sering kita saksikan, bukan hanya anak dewasa yang melakukan, bahkan anak yang masih remaja pun juga melakukanya, bahkan hingga sang korban meninggal dunia karena kekerasan yang mereka 
lakukan. Sebagai contoh tindak kekerasan yang terjadi yaitu tawuran antar pelajar, pemerkosaan anak di bawah umur, dan seterusnya. Kesemuanya adalah kenyataan yang sangat memperihatinkan akhlaq yang tengah menimpa bangsa Indonesia. Salah satu penyebab krisis akhlaq adalah karena kurang memperhatikan tuntunan agama, Salah satu cara mengurangi dan menanggulanginya adalah dengan pendidikan.

Pendidikan seyognyanya menjadi kebutuhan primer di zaman sekarang, pendidikan setidaknya menjadi identitas diri menjadi manusia yang berkualitas dan memiliki cita-cita tinggi yang diharapkan, karena pendidikan intinya adalah mendorong seseorang menjadi lebih baik dalam semua hal. Pendidikan dilakukan secara terus menerus, dan pendidikan akan menghasilkan out put yang maksimal apabila bersamaan dengan penanaman nilai-nilai keimanan yang seimbang.

Pendidikan agama dalam hal ini adalah agama islam dengan tujuan membentuk insan kamil. Adapun yang menjadi bidang kajian pendidikan agama adalah mengatur hubungan manusia dengan tuhan, manusia dengan manusia, dan manusia dengan alam. Oleh karena itulah, pendidikan agama adalah bagian dari pendidikan yang terpenting untuk menanamkan sikap dan norma-norma agama islam. Di samping itu dalam pendidikan diperlukan seorang pendidik. Seharusnya, individu yang berprofesi sebagai pengajaar atau pendidika tidak hanya menerapkan pengetahuan yang sesuai dengan kompetensinya, namun juga ilmu agama termasuk mengajarkan akhlaq.

Kehidupan yang semakin maju dan modern telah merubah segala hal, termasuk nilai-nilai agama seharusnya diimplementasikan dalam aktivitas sehari-hari mengalami kemunduran sehingga berakibat rusaknya akhlaq bangsa ini. Dalam hal ini yang biasanya terkena pengaruh, karena masa remaja merupakan masa kegoncangan emosi akibat perubahan dalam pertumbuhan diri.

Seorang pendidik yakni Guru, memegang peran penting dalam pendidikan karena ia bertanggung jawab penuh atas anak didik di sekolah, memberikan contoh yang baik. Guru tidak hanya mentrasfer ilmu pengetahuan saja namun juga mengarahkan, membina, dan membentuk perilaku anak didik, terlebih guru pendidikan agama islam. Teladan, sikap yang dilakukan oleh guru akan berimbas pada pembentukan karakter perilaku anak didiknya.

Dari sekian guru mata pelajaran, guru pendidikan rohanilah yang berperan sebagai pilot dalam menciptakan dan mananamkan akhlaq siswa. apabila gurunya tidak berakhlaq baik tentu siswanya tidak akan berakhlaq 
baik. Usaha guru dalam membina akhlaq siswa sangat mempengaruhi dalam proses pembentukan kepribadian anak didik. Dalam proses pembentukan akhlaq tentu tidak mudah, banyak kendala yang dihadapi guru, dan guru pendidikan agama islam harus bisa mengatasinya.

Seorang yang mempunyai keimanan menjadikan akhlaqnya sebagai cara mengimplementasikan keimanan kepada Allah SWT. Akhlaq merupakan cerminan kepatuhan terhadap agama yang menjadi bekal di dunia dan akhirat nanti, tetapi pencapaian perilaku akhlaq yang mulia perlu adanya pendidikan, salah satunya adalah pendidikan akhlak. Dengan adanya beberapa pemaparan diatas,maka bahasan pada penelitian ini dibatasi pada akhlaq saja.

\section{Metode}

Penelitian kualitatif adalah penelitian yang berlandaskan pada filsafat postpositivisme, digunakan untuk meneliti pada kondisi obyek yang alamiah (Sugiyono, 2015: 15). Penelitian kualitatif lebih diidentikkan dengan penelitian yang semua hasil datanya didiskripsikan dalam bentuk kata-kata. Dengan penelitian lapangan peneliti terjun dan terlibat lang sung dalam kelompok atau lingkungan penelitian, sehingga informasi yang didapatkan lebih akurat.

Karena penelitian kualitatif, maka data yang diperoleh dari penelitian ini adalah observasi, wawancara, dan dokumentasi.

\section{Observasi}

Observasi adalah peninjauan secara cermat (A. Hasan, 2007). Dalam tehnik ini lebih banyak peneliti memperoleh dataa dari pengamatan kepada obyek primer dan sekunder dalam rangka menunjang proses pembinaan ahlak siswa.

Observasi biasa disebut juga proses mengamati obyek penelitian dimana lokasi pelaksanaan dan pembinaan dan kondisi siswa saat proses berlangsung.

\section{Wawancara}

Wawancara adalah percakapan dengan maksud tertentu yang dilakukan oleh dua pihak, yaitu pewawancara yang mengajukan pertanyaan dan yang diwawancarai yang memberikan jawaban atas pertanyaan itu (Moleong, 2011: 146).

Tehnik ini dilakukan dengan cara bertemu dan interview langsung kepada nara sumber sehingga peneliti mendapatkan data yang sesuai daan akurat terkait penelitian yang dibahas. 
Dalam pelaksanaanya peneliti memberikan kuesioner kepada obyekobyek primer yang mengetahui permasalahan pembinaan akhlaq siswa di Sekolah Menengah Pertama Al-Azhar Pagelaran Malang, di antaranya melakukan wawancara kepada Kepala Sekolah SMP Al-Azhar Pagelaran Malang.dan Guru PAI Sekolah Menengah Pertama Al-Azhar Pagelaran Malang.

\section{Dokumentasi}

Dokumentasi adalah mencari data mengenai hal-hal atau variabel yang berupa catatan, Transkrip, buku, surat kabar, majalah, dan sebagainya (Arikunto, 2010).

Adapun data dokumentasi adalah data yang berupa berkas atau buktibukti secara redaksioner yang bisa mendukung dan menjawab masalah dalam penelitian seperti album sekolah, struktur kepengurusan sekolah, Visi misi dan lain sebagainya.

\section{Pembahasan}

Berdasarkan penelitian yang peneliti dilaksanakan mulai tanggal 21 April 2018 sampai 8 Mei 2018 di SMP Al-Azhar Pagelaran, maka dapat diketahui hasil penelitian mengenai Peran Guru PAI dalam Pembinaan Akhlaq Siswa di Sekolah Menengah Pertama Al-Azhar Pagelaran, yakni:

\section{Peran Guru PAI dalam Pembinaan Ahlak Siswa di Sekolah Menengah Pertama Al-Azhar Pagelaran Malang}

Peran Guru PAI dalam Pembinaan Akhlaq Siswa sangatlah penting. sebagai guru tidaklah mudah guru harus bertanggung jawab penuh atas siswanya. Sebagai guru juga harus profesional berdasarkan ketentuan yang telah ditentukan oleh pemerintahan. Berdasarkan hal ini, mengacu pada hasil data yang didapatkan peneliti, baik dari hasil wawancara, data dokumen maupun observasi dari informan bahwa peran guru PAI di SMP Al-Azhar Pagelaran adalah :

a. Peran guru Pendidikan Agama Islam sebagai guru yakni di Sekolah Menengah Pertama Al-Azhar Pagelaran ini guru PAI berperan menjadi guru yakni guru yang memang guru maksudnya adalah guru yang profesional

b. Peran guru PAI sebagai orang tua yakni menjadi orang tua kedua dari peserta didik yakni sebagai pembimbing siswa.

c. Peran guru sebagai teman yakni menjadi sahabat yang selalu membuat nyaman temanya dan teman ketika dalam masalah yakni sebagai motivator siswa. 
Hal ini berdasarkan teori Syaiful Bahri Djamarah dalam buku Guru dan Anak Didik dalam Interaksi Edukatif menyebutkan bahwa peran guru PAI adalah mengoreksi, memberi inspirasi, memberi informasi, pemimpin, motivator. Seperti yang diuraikan di bawah ini :

a. Guru sebagai korektor

Guru seyoyanya sebagai pendidik harus bisa memberi pengetian tentang perilaku baik dan buruk, kedua nilai yang berbeda itu harus betul-betul dimengerti dalam implementasi di masyarakat, dan adanya kedua akhlak tersebut pasti sudah ada dalam diri peserta didik sebelum mereka belajar di lembaga formal, sedangkan penerapan nilai yang bagus harus dipertahankan dan nilai yang jelek harus dirubah ketika sudah belajar dilembaga pendidikan, apabila guru tidak merubah tingkah laku yang jelek, berarti guru telah mengabaikanya. Yang menilai dan mengoreksi semua sikap dan tingkah laku anak didik, guru harus mengoreksi sikap dan sifat anak didik tidak hanya di sekolah namun juga di luar sekolah karena pembinaan akhlaq tidak cukup jika hanya dilakukan di Sekolah Menengah Pertama Al-Azhar Pagelaran.

b. Guru sebagai inspirator

Sebagai pemimpin dalam kelas, guru dituntut agar mempunyai tingkat intelegensi yang baik dan perilaku yang baik pula karena sebagai contoh bagi anak didik. Inspirator dalam pengertiannya adalah contoh, panutan. Sebagai inspirator dalam kelasa, guru harus bisa memberikan hal-hal yang dirasakan membangun bagi peserta didiknya. Guru mmepunyai tanggung jawab agar bisa memberikan solusi dan jalan keluar pada masalah-masalah yang dihadapi siswanya terkait dengan pembelajaran baik didalam atau diluar kelas.

c. Guru sebagai informatory

Informatory bisa diartikan bahwa guru PAI berperan memberikan informasi kepada peserta didiknya yang berhubungan dengan ilmu pengetahuan dan teknologi, dan hal-hal lain mengenai sub-tema yang telah ada dalam rancangan kurikulum yang telah ditentukan, sehingga pengajar memerlukan sumber yang valid dalam mendapatkan informasi. Sebagaimana dalam pembinaan akhlaq menjadi pedoman kehidupan sehari-hari bagi siswa di Sekolah Menengah Pertama Al-Azhar Pagelaran.

d. Guru sebagai organisator

Organissai dalam implementasinya berarti tentang pengelolaan yang dilakukan dalam keadaan tertentu. Terkait dengan guru sebagai organisator berarti guru mempunyai fungsi dan tugas dapat mengelola semua kegiatan yang ada dalam kelas atau sekolah yang berkaitan 
dengan akademik terkait dengan peningkatan mutu lulusan dalam lembaga pendidikan. Ketika seorang pendidik dapat berperan sebagai organisator, maka suasana yang terjadi dalam kelas akan kondusif karena guru dapat mengelola dan mengendalikan murid secara baaik sehingga proses belajar mengajar dapat terlaksana secara maksimal

e. Guru sebagai motivator

Dalam proses belajar mengajar dan didalam kelas, guru adalah sosok yang menjadi contoh bagi peserta didik. Tak jauh beda ketika guru berperan sebagai motivator, selayaknya guru dapat memberikan motivasi dan sebagai sumber semangat yang menjadikan sang murid giat dan aktif dalam proses belajarnya. Guru harus mampu mengidentifikasi dari gejala-gejala yang timbul ketika sang murid mulai malas atau tidak memperhatikan pelajaran dalam kelas sehingga menyebabkan prestasinya menurun, sehingga ketika guru sudah dapat mengidentifikasi gejala-gejala tersebut diharapkan guru akan dapat memberi solusi dan motivasi sehingga gairah belajar sang siswa kembali tertanam dalam diri.

\section{Upaya Guru PAI dalam Pembinaan Akhlaq Siswa di SMP Al-Azhar Pagelaran}

Upaya yang dilakukan guru pendidikan agama islam dalam pembinaan akhlaq siswa sangat berpengaruh terhadap hasil pembinaan yang diinginkan. Upaya upaya yang dilakukan oleh guru pendidikan agama islam Sekolah Menengah Pertama Al-Azhar yaitu : Pembelajaran pendidikan agama islam melalui keteladanan dan kedisiplinan seperti membuang sampah pada tempatnya, mengerjakan tugas tepat waktu, Melaksanakan kegiatan hari besar. Di antara kegiatan yang dilakukan di Sekolah Menengah Pertama Al-Azhar yaitu maulid nabi Muhammad SAW, memperingati Tahun baru islam, dan Isra' Mi'raj. Kemudian dengan melakukan sholat dhuhur berjamaah, dengan sholat dhuhur berjamaah akan timbul sifat disiplin siswa.

\section{Faktor Pendukung dan Penghambat Pembinaan Akhlaq Siswa di Sekolah Menengah Pertama Al-Azhar Pagelaran}

Faktor pendukung pembinaan akhlaq di Sekolah Menengah Pertama AlAzhar Pagelaran yaitu :

a. Faktor keluarga

Keluarga merupakan komponen penting dalam pembinaan akhlaq sebelum guru, karena siswa hidup setiap hari bersama keluarga, baik buruknya ahlak tergantung bagaimana keluarga mendidiknya.

Hal ini berdasarkan teori Zakiah Darajdat yang berpendaapat bahwa awal dasar pembentukan karakter dan perilaku akhlak dari seseorang 
adalah dari lingkungan keluarganya. Adapun guru yang pertama bagi seseorang adalah orang tua yang seyognyanya didapat dari lingkungan keluarga. Peran orang tua dan anggota keluargasangat menentukan masa depan anaknya.

b. Adanya tata tertib sekolah atau peraturan sekolah

Dengan adanya peraturan sekolah siswa akan mengikuti pembinaan ahlak, karena takut ataupun jera terkena sanksi.

c. Osis Sekolah Menengah Pertama Al-Azhar Pagelaran

Dengan adanya Organisasi sekolah kegiatan di sekolah akan lebih ringan seperti kegiatan memperingati hari besar islam.

d. Faktor Lingkungan

Lingkungan mnentukan baik buruknya ahlak siswa, ketika siswa berteman bolos maka warga yang melaporkan kepada pihak sekolah.

Selain faktor pendukung pembinaan akhlaq juga ada faktor penghambat pembinaan akhlaq di Sekolah Menengah Pertama Al-Azhar Pagelaran, yaitu :

1. Faktor Lingkungan

Lingkungan sekitar sangat berpengaruh dalam pembinan karena siswa mempunyai kesempatan kabur ke rumah warga.

2. Jarak rumah siswa

Jarak rumah siswa yang dekat akan sering bolos saat pembinaan karena mereka pulang saat pembinaan berlangsung. Jarak rumah yang jauh akan membuat siswa malas mengikuti pembinaan.

3. Terbatasnya pengawasan pihak sekolah

Guru tidak mungkin mengawasi akhlak siswa selama 24 jam, karena tidak mungkin guru setiap saat mengawasi akhlaq siswa Sekolah Menengah Pertama Al-Azhar Pagelaran .

4. Adanya hari libur yang panjang

Setelah libur panjang seperti libur karena ada ujian nasional, siswa di Sekolah Menengah Pertama Al-Azhar Pagelaran cenderung lebih malas dari sebelum libur.

\section{Kesimpulan}

Setelah melakukan proses penelitian, pengkajian dan pembahasan mengenai penelitian yang berjudul peran guru Pendidikan Agama Islam di Sekolah Menengah Pertama Al-Azhar Pagelaran, maka peneliti atau penulis memberikan kesimpulan sebagai berikut:

1. Peran guru yang dilakukan di Sekolah Menengah Pertama Al-Azhar Pagelaran berperan sebagai :

a. Guru sebagai pemimpin dikelas 
b. Guru sebagai orang tua

c. Guru sebagai teman

2. Peran guru Pendidikan Agama Islam Sekolah Menengah Pertama AlAzhar Pagelaran mempunyai pengaruh besar terhadap siswa, karna guru PAI di SMP Al-Azhar Pagelaran sangat berperan aktif dalam pembinaan akhlaq siswa, kegiatan pembinaan yang dilakukan guru yaitu:

a. Pembinaan saat pembelajaran Pendidikan Agama Islam

b. Melaksanakn kegiatan Memperingati Hari Besar Islam

c. Sholat dhuhur berjamaah

3. Faktor pendukung pembinaan akhlaq siswa di Sekolah Menengah Pertama Al-Azhar Pagelaran yaitu :
a. Faktor keluarga
b. Adanya peraturan sekolah
c. Osis Sekolah Menengah Pertama Al-Azhar Pagelaran
d. Faktor Lingkungan

Sedangkan faktor penghambat pembinaan akhlaq siswa di Sekolah Menengah Pertama Al-Azhar Pagelaran yaitu :

1. Faktor Lingkungan

2. Jarak Rumah Siswa

3. Waktu yang Terbatas

4. Hari libur panjang

\section{Daftar Rujukan}

Abdul Wahid Hasan. 2006. SQ Nabi Aplikasi strategi di masa kini. Yogyakarta: IRCioD

Ahmadi, Ahmad. 2002. Metodologi Penelitian. Jakarta: Bumi Aksara

Azzet, Akhmad Muhaimin. 2010. Mengembangkan Kecerdasan Spititual Bagi Anak. Cet,I, Jogjakarta: Katahati

Burzan, Tony. 2003. cara menjadi orang yang cerdas spiritual. Jakarta: PT Gramedia Pustaka Utama

Derajat, Zakia. Dkk. 2008. Ilmu Pendidikan Islam. Jakarta: Bumi Aksara

Etta Mamang Sangadji dan Sopiah. 2010. Metodologi Penelitian. Cet.I, Yogyakarta: C.V Andi Offset

Fuaidi, Nur. 2012. Profesional Guru. Purwokerto: STAIN Press

http://Pendidikanku.org/2016/09pengertian-kecerdasan-dan-macammacam.html?m= 1 (Diakses pada tanggal 3-02-2019 pukul 09.00)

Idrus, Muhamad. 2009. Metode Penelitian Ilmu Sosial. Cet. II, Yogyakarta: PT Gelora

Aksara Pratama 
Ihsan, fuad. 2003. Dasar-dasar Kependidikan. Cet.III, Jakarta: Rineka Cipta

Lubna. 2009. Mengurangi Ilmu Pengetahuan Islam. Mataram: LKIM

Majid, Abdul dan Dian andayani. 2006. Pendidikan Agama Islam. Bandung: Remaja Rosdakarya

Maleong, J Lexy. 2009. Metode Penelitian Kualitatif. Bandung: Alfabeta

Marshall dan Zohar. 2002. Memanfaatkan Kecerdasan Spiritual. Bandung: Mizan

Muslich, Mansur. 2011. Pendidikan Karakter, Menjawab Tantangan Krisis Multidimensional. Jakarta: Bumi Aksara

Nata, Abudin. 2010. Ilmu Pendidikan Islam. Jakarta: Kencana

Nurdin, Muhammad. 2009. Kiat Menjadi Guru Profesiona. Jogjakarta: ArRuzz Media Grub

Steven J. Stein dan Howard E. Book. 2002. Ledakan EQ 15 Prinsip Dasar Kecerdasan Emosional Meraih Sukses. Bandung: Kaifa

Sukidi. 2004. Kecerdasan Spiritual SQ Lebih Penting Dari Pada IQ dan EQ. Jakarta: PT Gramedia Pustaka Utama

Syaifudin sa'ududin. 2008. Pengembangan Profesi Guru. Cet.II, Bandung

http://kbbi.web.id/upaya.dedipnas,2008. (Dikutip pada tanggal 28-1-2019 pukul 10.00) 